\title{
Conceptualizing lay participation in professional health care organizations
}

\author{
Benjamin Marent*, Rudolf Forster and Peter Nowak \\ *School of Applied Social Science, University of Brighton \\ b.marent@brighton.ac.uk
}

Published in: Administration \& Society 2015, Vol. 47(7) 827- 850

DOI: 10.1177/0095399713489829

http://aas.sagepub.com/content/47/7/827

\begin{abstract}
The participation of lay people in health care decision-making lacks an adequate analysis from an organizational perspective. This article aims to develop conceptual devices to analyze policies and practices and to discuss ways in which these policies and practices could be further developed. By recapping established frameworks and drawing on theories of professional organizations, four roles for the participation of lay people and their potential to adapt organizational decision processes to internal requirements and external challenges are elaborated. While individual patient participation is widely acknowledged, there is still a lack of systematic approaches to the roles of significant others, patient groups and the broader community and their implementation within health care organizations.
\end{abstract}

Keywords: Lay participation, health care organization, patient participation, public participation, decision making

\section{Introduction}

Lay participation in health care policy, planning and management has been a prominent theme since the emancipatory social movements of the 1960s (White, 2000). A cultural change is noted in which the authority of experts has gradually been challenged by citizens and users of services who lay claim to more possibilities for participation (Gerhards, 2001). Drivers for this change are seen mostly in the higher levels of education of lay people, in new communication technologies and in the emergence of post-materialist values (ibid.). The World Health Organization formally took up these demands in 1978 by acknowledging that the "people have the right and duty to participate individually and collectively in the planning and implementation of their health care" (WHO, 1978, p. 1). Subsequent WHO policy documents have confirmed this perspective. The issue of participation is now high on the agendas of governments and health policy makers all over the world, especially in the UK, the USA, Canada and Australia (Forbat, Hubbard, \& Kearney, 2009). Yet this trend is put into practice rather differently (Tambuyzer, Pieters, \& Van Audenhove, 2011). Participation often does not work as intended (Rise et al., in press) and the impact of participation is, as yet, largely undetermined (Tritter, 2009). 
One of the reasons for this is "the conceptual muddle with which involvement is articulated, understood and auctioned" (Forbat, Hubbard, \& Kearney, 2009, p. 2547). Nevertheless, most definitions of participation acknowledge that it is about gaining influence on decisions which are taken by established stakeholders legitimized by expertise and/or legal authority and over which those who are affected usually have very little control.

A further reason for the difficulties of conceptualizing and specifying participation lies in its situational character: within and, even more, across contexts, participation relates to different categories of lay people, serves different functions, involves different issues and implies different forms and methods of implementation. Some progress has been made in identifying and specifying the basic dimensions of participatory initiatives for various contexts related to health (see below).

Considering the abundance of participatory endeavors in health issues and the vast literature relating to policy and practice, it is striking that health care organizations seem to have taken up lay participation rather rarely and in a limited way. Reflecting this, research so far has only marginally addressed the specificity of organizations for shaping participation. This might be due, in part, to the emergence of market-related concepts and policies which suggest "consumer choice" as a more lean and efficient strategy than "voice" (participation) for promoting responsiveness, quality and efficiency in public service organizations (Le Grand, 2007). Yet there is doubt that choice alone is sufficient for organizational innovation or that it can replace the need for taking into account the perspectives ("voice") of service users in a differentiated way (Mintrom, 2003). This holds especially for those complex human services where providers and clients find themselves in mutually reinforcing relationships of "co-production" (ibid., p. 53). Furthermore, to take the aggregation of individual choices as proxy for public involvement (Tritter, 2009) implies a very limited and instrumental understanding of citizenship and cuts off the discourse on common values and the public good (Fafard, Rocher, \& Coté, 2009).

The aim of this article is to develop conceptual devices to analyze policies and practice of lay participation in the context of health care organizations and to discuss ways in which lay participation could be further developed. We will start off by recapitulating the essential questions that have been addressed by various frameworks for analyzing participation (who, what, why and how). In a next step, we portray health care organizations as professional, people-changing organizations and the way the role of users/clients in this context is typically understood. We then ask which roles lay people may take over when participation is considered as a strategy in health care organizations to better adapt their programs to the needs and demands of users and communities. We use this lens to analyze current policies and practices of lay participation in health care organizations and finally we discuss how lay participation can be facilitated and developed further in this context.

\section{Frameworks for lay participation in health issues}

How can lay participation in health issues be understood, planned, implemented and evaluated? Among the numerous attempts that have been made over the past 40 years to propose classifications, models or frameworks for answering these questions, two papers stand out: The first is the "ladder of participation" by Arnstein (1969) which centers around 
the issue of citizen-power in participation; the second is a more complex but also more specific framework by Charles and DeMaio (1993) related to lay participation in health care and policy decision-making.

Arnstein (1969) developed her model for a critical appraisal of the proclaimed participation of citizens in urban development projects in the USA. For her, the essence of participation is decision-making power and her ladder is designed to provide a tool for unmasking "empty" and "frustrating" forms of participation that just maintain the status quo while using participation-rhetoric. Accordingly the eight rungs of the ladder represent increasing degrees of citizen influence. Only participation on the top rungs, which includes delegation of power by traditional power-holders to citizens and is topped by "citizen control" is considered "genuine"; participation on the middle rungs which involves citizens indirectly (e.g. information or consultation) is considered to be "tokenism"; and the bottom rungs represent non-participation which, nevertheless, masquerades as participation. Arnstein's model has been taken up widely in many areas of policy and practice, among them health policy, health care and health promotion, often in a revised form by adding, removing or renaming rungs of the ladder (for an overview see Tritter \& McCallum, 2006). Obviously, Arnstein's perspective captured an essential dimension of participation while, at the same time, fulfilling the desire for neat and manageable categories (Labonte, 1997).

Charles and DeMaio (1993) suggested their framework in the context of an analysis of Canadian participation policies in the health sector to specify more precisely the meaning of lay participation and to provide a systematic way to classify the wide range of different participatory approaches. This framework has three key dimensions: The first refers to different decision making domains, i.e. the issues to be decided upon (which implicitly refer to the other stakeholders involved). Three sub-categories of this dimension are distinguished: treatment of individual patients; service delivery for a defined region or a particular health care facility; and macro health care policies. A second dimension addresses the role perspective which is assumed by the participants. Two generic perspectives are suggested here: a user perspective which reflects more concentrated or particularistic interests, and a public policy perspective which reflects broader interests and the common good. The third dimension called "level of participation" refers to the degree of power or control conceded to lay people, for which Arnstein's ladder is collapsed into three grades: consultation, partnership and lay control. By combining domains and role perspectives, Charles and DeMaio illustrate six different types of lay participation in health care and policy in which the level of participation may vary. In addition to their systematic effort, Charles and DeMaio also reflect on the meta-question of what the goals of lay participation are or should be. - These essential dimensions (goals, roles, issues, and level) or questions (why, who, what about, and how) can be traced in recent frameworks which conceptualize lay participation in various health-related areas, as e.g. health technology assessment (Gauvin et al., 2010), health services research (Oliver et al., 2008), health promotion (Llewellyn-Jones \& Harvey, 2009), mental health care (Tambuyzer, Pieters, \& Van Audenhove, 2011) and health policy (Tritter, 2009). Their importance is also underlined by frameworks elaborated for nonhealth related areas such as participatory evaluation (Daigneault \& Jacob, 2009).

What can be learned from these frameworks for the analysis of lay participation in health care organizations? First, some of the dimensions are highly context-bound and have 
to be specified for the particular context in mind. This holds especially for the question "participation in what" which requires an analysis of the typical issues decided upon. For the goals of participation (the question why?) two basic rationales are provided (Charles \& DeMaio, 1993, Tenbensel, 2010): participation can either serve as a contribution to more democracy by empowering citizens, emphasizing dialogue, strengthening social capital and common values or it may be seen more narrowly as a means to an end, to increase the acceptance, quality and effectiveness of particular programs and services. With respect to the role perspectives (the question of who?) the distinction between users and the public has been introduced already. The participation of a "disinterested" public (Tenbensel, 2010, p. 1538) with no vested interests and little prior knowledge is mainly argued for generic issues and for advocating the broader common good. One of the crucial questions is who constitutes the public and who may represent it appropriately. Accordingly, different types of publics may be distinguished (Gauvier et al., 2010). Participation of those affected by particular decisions relates to more specific issues; it is based on individual needs and preferences as well as the unique experience of being a user. Recently, collectives of users have gained importance as an additional role perspective which may oscillate between particularistic and public interests (Litva et al., 2009).

By contrast to these situation-bound dimensions, the question of how participation can be put into practice and observed seems to be rather generic. Most frameworks adhere to a hierarchical approach which is more or less based on Arnstein's ladder. Recently, critical debates have been raised relating to its one-dimensional (reductionist), static and normative character without having been replaced by a convincing alternative (Tritter \& McCallum, 2006). By contrast to understanding participation as a struggle for power, Tritter (2009) underlines the opportunities created by assembling different actors with different experiences in a mutual exchange of knowledge as an additional perspective. Several authors (e.g. Charles \& DeMaio, 1993) consider decision-making as a dynamic process encompassing a number of different phases. The relevance of taking part in deliberations and not only in the act of determination has been extensively argued by Elwyn and MironShatz (2010). Other authors emphasize the developmental character of participation, conceive participation as a learning process and assign a more positive connotation to lower levels of participation (Simovska \& Jensen, 2009; Wright, Block, \& von Unger, 2008). Overall, all these arguments refer to the "quality of participation" rather than solely looking at the quantity of influence conceded. The interest in developing methods and techniques for instigating participation (Abelson et al., 2003; Tenbensel, 2010) partly also reflects this concern. Taking up the critique on the lack of complexity, we suggest complementing the power-dimension with a separate dimension relating to the knowledge and experience of the actors involved. Drawing on a system theory perspective on decision communication (Luhmann, 1995), the dimension that refers to formal control and power is called the social dimension of participation, while the dimension that refers to the opportunity to bring in knowledge and experience and to expand the spectrum of topics and the way they are defined is called the factual dimension of participation. In addition, several indications of a temporal dimension are taken up to acknowledge that participation may vary in different phases of decision-making processes. In this dimension, it can be asked when and for how 
long participants become involved. The following figure summarizes the analytical differentiations used in this article.

\begin{tabular}{|c|c|c|}
\hline \multicolumn{3}{|c}{ Context of lay participation } \\
\hline $\begin{array}{c}\text { Why? } \\
\text { [goals/functions] }\end{array}$ & $\begin{array}{c}\text { Who? } \\
\text { [roles] }\end{array}$ & $\begin{array}{c}\text { What about? } \\
\text { [issues] }\end{array}$ \\
\hline \multicolumn{2}{|c}{ Form of lay participation } \\
How? \\
\hline $\begin{array}{c}\text { Social dimension } \\
\text { [power] }\end{array}$ & $\begin{array}{c}\text { Factual dimension } \\
\text { [knowledge] }\end{array}$ & $\begin{array}{c}\text { Temporal dimension } \\
\text { [phases] }\end{array}$ \\
\hline
\end{tabular}

(Figure 1: A general framework for analyzing lay participation in health issues)

In the next section we will characterize health care organizations as a specific context for the participation of lay people and elaborate on the roles lay people may take over, on the issues that may become the topics of participation and on the functions participation may fulfill. Having set the stage, we then turn to an analysis of the social, factual and temporal aspects of current participatory policies and practices in health care organizations.

\section{Professional health care organizations}

Health care organizations encompass a wide variety of organizations. In this article we refer to more complex organizations in which certain levels of division of labor between different health care professions as well as a separate management structure have been developed. Hospitals can be considered as the prototypical organization we have in mind, but the arguments also hold for rehabilitative or other specialized medical institutions. Such health care organizations represent a type of organizations which Mintzberg (1979) portrayed as "professional bureaucracies". With this concept, he emphasizes analogies between health care organizations (e.g. hospitals), educational organizations (e.g. schools, universities) and law organizations (e.g. law firms, courts). In these, the formal division of labor is shaped as much by the interest of professions as by the principles of managers (Kirkpatrick, Dent, \& Jespersen, 2011). In all professional organizations, the work on the operative level is carried out by various professionals interacting directly with clients to change their physical, mental or social status. Within the health care professions, medicine still takes a dominant role over the so-called semi-professions and other allied health professionals, despite the striving of these professions for more autonomy and more symmetric working relations (for nursing e.g. Witz, 2006).

Professional interventions in health care have been described as "people-changing programs" (Hasenfeld, 1983) that are complex and often take place under conditions of uncertainty and risk. Professional work is founded upon knowledge acquired during long periods of education and training. Yet there are serious limits to applying this knowledge in highly complex and ambiguous situations. In such situations, professionals, e.g. surgeons, also have to act when they are confronted with complications that have not yet been defined by medical science. To enable professionals to act in a situation-dependent way and take decisions intuitively, based on knowledge and experience and related to the particular 
case, health care organizations grant their professional staff considerable autonomy. Thus, the standards according to which professionals categorize and treat their clients largely originate from outside of the organization - in academic institutions and professional associations - while their application in specific situations implies autonomy and discretion. Professions are reluctant to concede external control over their work, so they seek control over administrative decisions in organizations by staffing mid-level management positions with members of their own profession and by enforcing "collegial" mechanisms of managerial control (Mintzberg, 1979). The professional's definition of the treatment situation is usually supported and legitimized through the symbolic use of specialized language, high-tech instruments or the presence of subordinate staff. However, many factors in the success of the complex intervention into the patients' health lie beyond the professional's control and are dependent on the motivation and collaboration of the client.

Clients are included in patient roles through diagnostic programs that are followed by various treatments. These processes take place in close interaction between professionals and the individual patient, which is characterized by a highly asymmetric structure. Authority based upon knowledge and decision control are vested in the professional and patients are expected to trust in the professional's competence and altruism for effective professional performance (Stichweh, 2005). To further facilitate professional work, insulation of professional-patient relations against external interference is a typical strategy (Hasenfeld, 1983). However, the goal attainment of professional performance depends to a considerable degree on the "co-production" of patients, implying involvement in decisions on the planning and collaboration in the course of treatment and care.

As people-changing programs rely on co-presence in critical situations, patients often become totally included in health care organizations over a certain period of time and must, therefore, fulfill all their needs within one organization. Consequently, people-sustaining programs (Hasenfeld, 1983) relating to patients' accommodation, nutrition, personal hygiene, psychosocial well-being etc. become an essential part of some health care organizations. These programs are mostly carried out by support staff (e.g. auxiliary nurses) under the authority of professional nurses.

The role of the management in health care organizations is to monitor peoplechanging and people-sustaining programs and to further develop them according to the organizations' external pressures. Moreover, it has to coordinate treatment processes between different departments and specialties and even with other organizations. Hasenfeld (1983) refers to these programs as "people-processing". However, Mintzberg (1979) argues that the role of management is relatively weak in professional health care organizations and only loosely coupled to the operative level. Values and the expertise of medical professionals are well established and firmly rooted in science as well as academic and professional institutions. Therefore they cannot easily be questioned by managerial authority. Yet increasingly, health care professionals are being challenged by managerial, market and political forces (Hunter, 2006). Managers have been encouraged to supervise medical work more directly by monitoring output and results, demanding discipline in resource use, extending provider competition and emphasizing the public as consumers (ibid.). A recent literature review (Numerato, Salvatore, \& Fattore, 2012) analyzed the impact of these challenges on professional practice and culture: It demonstrated that professionals employ 
various strategies to co-opt, negotiate or reverse managerialism and concluded that there is no evidence of "de-professionalization". In health care organizations, the management still faces difficulties in observing and evaluating the operative level and in developing and implementing new strategies that may be required in accordance with the dynamic changes within the organization's environment.

\section{Participation as an organizational strategy to adjust to changes from the demand-side}

Health care organizations work in a turbulent environment. Pressures for change can come from the demand-side (demographics, patterns of disease, public expectations), the supply side (technology and clinical knowledge, health care work force) or the wider society (financial pressures, global market) (McKee, Healy, Edwards, \& Harrison, 2002). To adjust to these changes, health care organizations rely on organizational structures to observe and enact (Weick, 1979) the needs and sensibilities of their environments.

Since health care organizations provide their core function for and with lay people, responding to demand-side changes is a major task for these organizations. In a "knowledgesociety", professional knowledge is more and more absorbed by the lay public and willingness to critically observe and assess professional work is increasing (Stichweh, 2005; Vanderstraeten, 2007). Living with chronic conditions involving continuous medical treatment over long periods of time constitutes a new body of "experiential knowledge" on the side of patients (Borkman, 1976). Building structures to engage more closely with lay people can be regarded as a strategy through which these relevant changes become observable for organizations.

On the operative level, the extent to which the life world of clients becomes relevant for people-changing processes depends largely on the way in which the patient role is constituted. The success of these processes essentially relies on considering the patient's social and cultural background since it is from this background that patients interpret decisions about their treatment and recovery.

The task on the management level of health care organizations is to make decisions on service development by observing and evaluating internal processes as well as needs and expectations in the external environment. Aging populations, migration, changes in risk factors, lifestyles and education do affect medical patterns of disease but also social needs and expectations of health services (McKee, Healy, Edwards, \& Harrison, 2002). In this respect, health care organizations must ensure that they are sensitive to different cultural traditions (e.g. religion, diets, attitudes to family visiting, etc.), to populations with different levels of health literacy and to public expectations about the quality of services and involvement in treatment decisions.

Including lay perspectives in professional and managerial decisions could be one strategy to reorient health services towards changing demands and expectations in their environment.

\section{Lay participation in the context of health care organizations}

Within health care organizations, lay participation has, so far, been particularly emphasized by frameworks relating to the individual patient role, while collective public participation has 
been considered as relevant mainly for decisions addressing the health care policy level (Charles \& DeMaio, 1993; Church et al., 2002; Tritter, 2009).

Yet, building upon the organizational perspective elaborated above, we will argue that different types of lay people (who) can become relevant on different levels, for different organizational programs (what) and thus facilitate different functions (why). It is important to elaborate the significance of different lay people since in the organizational context, there is a need for a clear exposition of what lay participation means and may contribute - rather than relying on abstract rationales such as democratic accountability (Martin \& Finn, 2011).

In differentiating potential roles for lay participation, we draw two distinctions and thereby differentiate four roles: First, we refer to the distinction between the operative and the management level of health care organizations: On the operative level, professional health care organizations deal with individual clients and carers and their individual problems, needs and complaints. On the management level, lay people become relevant mostly when they represent a collective interest. The second distinction relates to the boundary between organizations and their social environment: The defining feature of belonging to the organization is a membership-role (Luhmann, 2003). Only lay persons eligible by diagnosis and severity of condition (and sometimes additional attributes such as ability to pay) may occupy a membership role as patients. This most visibly happens when patients are admitted as in-patients, but the patient role is also extended to former inpatients as long as they are regularly monitored. Not only individual patients, but also collectives of current or former patients may accomplish a quasi-"insider"-status, although in a much looser way. Lay people who do/did not occupy a patient role belong to the organization's environment. On the operative level, this environment consists mainly of a patient's significant others who usually have no defined role in health care organizations. On the management level, the environment refers to a community and its different "publics" who might have an interest in the organization's services. Taken together, these two distinctions create a spectrum of four roles for lay participation (figure 2):

\begin{tabular}{|c|l|l|}
\cline { 2 - 3 } \multicolumn{1}{c|}{} & \multicolumn{1}{c|}{ Organization } & \multicolumn{1}{c|}{ Environment } \\
\hline $\begin{array}{c}\text { Operative } \\
\text { level }\end{array}$ & Role: individual patient & Role: patient's significant others \\
& $\begin{array}{l}\text { Issues: treatment and care } \\
\text { facilitation of co-production }\end{array}$ & $\begin{array}{l}\text { Issues: treatment, care and } \\
\text { aftercare } \\
\text { Function of participation: } \\
\text { support of co-production }\end{array}$ \\
\hline $\begin{array}{l}\text { Management } \\
\text { level }\end{array}$ & $\begin{array}{l}\text { Role: patient groups } \\
\text { Issues: quality and integration } \\
\text { of services }\end{array}$ & $\begin{array}{l}\text { Role: community } \\
\text { Issues: responsiveness to } \\
\text { (neglected or new) needs }\end{array}$ \\
$\begin{array}{l}\text { Function of participation: } \\
\text { observation/evaluation of } \\
\text { internal processes }\end{array}$ & $\begin{array}{l}\text { Function of participation: } \\
\text { realigning the organization to } \\
\text { (new) expectations and demands }\end{array}$ \\
\hline
\end{tabular}

(Figure 2: participatory lay roles and related issues and functions in health care organizations)

Individual patient participation takes place on the operative level of health care organizations, which is dominated by professionals. Patients get included in the organization through diagnoses and thus occupy an established role with an immediate interest in the 
treatment process. Their active participation in treatment decisions and illness management (people-changing programs) has been promoted in recent years to counteract the traditional asymmetric relationship with professionals (Charles, Gafni, \& Whelan, 1997). Individual patient participation implies that patients' experiences become part of decisions on the planning and course of the treatment, which is considered to contribute to the coproduction of health.

Participation of patient's significant others refers to individuals situated in the organizational environment (carers, families or legal guardians of patients) who are affected by the patient's illness and by decisions taken during the treatment process. Significant others thus have an immediate interest in the treatment processes in which patients are involved. Their role becomes obvious when treatment processes and recovery are not completed within organizational boundaries but are, rather, embedded in primary social networks as is the case with many chronic conditions. The information and engagement of significant others in treatment processes and decisions is identified as a high priority in many health fields (e.g. pediatrics, geriatrics and mental health care) (Cleary, Freeman, \& Walter, 2006). Their involvement can contribute to an effective care plan and its integration and sustainment within primary social networks. However, it is important neither to overlook what significant others expect from their involvement nor to overburden them with responsibilities (ibid.).

Participation of patient groups: The experience of illness is very personal. This corresponds with the claim of professional health care that it is highly individualized and adjusts available treatment and support to the needs of an individual case. At the same time, organized medical work is highly standardized due to the fact that it is based on differentiating specific standardized cases (Mintzberg, 1979) and treatment procedures (e.g. evidence based medicine) and that patients become subject to imposed organizational routines (Stichweh, 2005). Thus, there are many commonalities in patient experience, not only of having a certain condition, but even more of being treated as a patient with a certain condition. The experience of regular use of health care services constitutes, to some degree, a common perspective, which is quite distinct from that of professionals and not easily accessible for health care management due to the autonomy of professional work. Patient groups (also called self-help or health consumer groups) for particular conditions as well as across condition areas have been growing in numbers over the past decades in many countries (Baggott \& Forster, 2008; Kelleher, 2006).The systematic inclusion of this perspective of patient collectives via a participative role could serve to broaden an organization's observation of its internal performance processes. This could provide information about deficits and flaws and be used to improve services in a way that would make them conform more closely to the needs of users.

Community participation refers to people situated in a health care organization's local environment and is relevant for the management level. The community represents not only potential users but also the broader public interest in the contribution that health care organizations can make to community and population health in general (Charles \& DeMaio, 1993). Accounting for their perspectives enables health care organizations to adapt to social changes by setting priorities and developing services that relate to everyday life circumstances and local needs (Tritter, 2009). Building structures to engage with local 
communities is considered a strategy to realign organizations with diverse and changing expectations, problems and resources in their external environments.

\section{Policies, practices and directions towards lay participation}

Participation in health care refers to different roles and issues and may serve different functions. In the following, we illustrate how the four roles of lay participation can be used to analyze various policies and practices of participation in health care. Furthermore, we make use of theories of professional organizations to discuss how different types of participation have been established and may be developed further.

A paradigmatic concept for implementing individual patient participation is "shared decision-making" (Barry et al., 2011; Charles, Gafni, \& Whelan, 1997; Edwards \& Elwyn, 2006). It refers to information and knowledge exchange (factual dimension) as well as shifting decision control (social dimension) between health professionals and patients. Edwards and Elwyn (2006) showed that patients benefit most from the deliberative process in shared decision-making: i.e. the information exchange between doctors and patients and the discussion of various treatment options. Through this process, treatment options become better adapted to the life situation of patients. By contributing to the elaboration of treatment alternatives, patients become empowered to understand and take an active role in decision-making and thus facilitate the co-production of their health. Appropriate involvement in deliberation is reported to increase patient satisfaction regardless of involvement (patient-led, shared or clinician-led) in the final decision-making (Edwards \& Elwyn, 2006).

Individual patient participation seems readily adaptable in health care organizations. Individual patients occupy an established role, their interest seems obvious and their contribution to the treatment process is increasingly acknowledged. As a professional concept, shared decision-making may be enhanced and implemented indirectly in organizations through professional education rather than by management fiat. However, the management could support the implementation of shared decision-making structurally by facilitating temporal and physical conditions. Moreover, the management can symbolically support patient participation through implementing 'patient centeredness' within general organizational programs such as the mission statement of the organization.

The relevance of patients' significant others has been especially acknowledged in the case of immature, elderly, mentally ill or specifically vulnerable patients and is emphasized by triadic concepts of treatment decision-making (cf. Gabe, Olumide, \& Bury, 2004; van Staa, 2011; Cahill \& Papageorgiou, 2007). Therein, significant others may facilitate knowledge exchange (factual dimension) between patient and doctor by translating information to patients, coaching them to ask questions and advising on the selection of treatment option, etc. (Charles, Gafni, \& Whelan, 1997). In some cases, significant others may even become substitute decision makers (e.g. as legal guardians) and are responsible for taking decisions on behalf of the patient (social dimension).

The participation of patients' significant others is often accompanied by certain ambiguities: Interaction with significant others is frequently not included in job profiles and organizational processes. They do not have a predefined organizational role; professionals 
may be unsure about their relationship to patients, their potentially conflicting interests and their resources (Cleary, Freeman, \& Walter, 2006). The temporal structure and the physical conditions of the organization may not be easily adaptable to the presence of accompanying persons (Gabe, Olumide, \& Bury, 2004). Furthermore, in cases where the role of significant others is well defined, as in the case of parents or legal guardians, the patient's role may become weakened. Research suggests that true partnering involving three actors is often difficult to achieve (Cahill \& Papageorgiou, 2007; Gabe, Olumide, \& Bury, 2004; van Staa, 2011). Particularly in pediatrics, it is reported that legal guardians build coalitions with doctors and thus the child patient is largely excluded in medical encounters (ibid.). Handling triadic communication within treatment processes relies largely on the professional's competence, which may be enhanced through education and training. Yet, triadic communication could also be supported by the organization's management through appropriate physical and temporal arrangements that allow the three parties to discuss their concerns conveniently (Gabe, Olumide, \& Bury, 2004) as well as by the symbolic underpinning of the relevance of significant others (carers) (Cleary, Freeman, \& Walter, 2006).

Participation of patient groups: The management of health care organizations increasingly uses aggregated data from surveys or complaints as the main source for understanding collective patient perspectives (Coulter, 2002). Patient groups have become better able to offer a more comprehensive lay perspective as they have built up a distinct body of "experiential expertise" through mutual exchange (Borkman, 1976). Yet experiential expertise (factual dimension) also creates a latent readiness to question the way health services are provided and to influence decisions (social dimension) on service provision (Kelleher, 2006). So far, an advocatory role for patient groups has rarely been developed through a coherent and comprehensive policy of granting such groups formal participation in health policy or health service provision (Löfgren, De Leeuw, \& Leahy, 2011). In fact, very little evidence exists on the participation of patient groups in individual health care organizations. Although such groups are often in close contact and supported by particularly engaged professionals, they rarely seem able to get access to and have influence on organizations (Forster, Braunegger-Kallinger, \& Krajic, 2011).

One of the few documented approaches for a systematic involvement of patient groups is the initiative for "self-help friendly" health services (especially hospitals) in Germany (Trojan \& Nickel, 2011). According to the results of this initiative, the establishment of participatory roles for patient groups in health care organizations is facilitated if this is embedded in a broader strategy of organizational development towards patientcenteredness and service quality. In particular, this includes a formalized agreement between groups and health care organizations, institutionalization of regular exchange, the denotation of professionals acting as contact persons, the inclusion of experiential expertise in further education of professionals, documentation and assessment and the inclusion of patient representatives in governance boards such as quality commissions (ibid.). Self-help support organizations, which have been established on a broad scale in Germany, act as bridging institutions between groups and health care organizations. On the one hand, they provide support and training for patient groups (ibid.). This is important as e.g., the Dutch experience on the participation of such groups in health policy shows that providing 
opportunities, but not enough capacities to cope with them, might lead to discouragement and instrumentalization (van de Bovenkamp, Trappenburg, \& Grit, 2009). On the other hand, the formal character and professional stance of the support institutions fosters the readiness of health care management to engage with a lay movement.

Community participation: Among modern welfare state health care systems, the National Health Service (NHS) in England is probably the one with the longest tradition in making formal arrangements to create a role for local communities vis-à-vis health service providers in addition to elected local politicians. As early as 1974, Community Health Councils (CHCs) were established, which represented community interests for about 30 years, monitoring local health services, informing the local public and representing community needs with their success depending heavily on the commitment of unpaid volunteers (Forster \& Gabe, 2008; Hogg, 2007). In 2003 - a period when patient and public involvement had become a cornerstone of a "patient-led" NHS - they were replaced by Patient and Public Involvement Forums (PPIF) which were more closely tied to provider institutions and user perspectives (ibid.). These institutions were again replaced by Local Involvement Networks (LINks) in 2008, emphasizing a "new localism" integral to a renewal of citizen engagement in the running of local public services (Hogg, 2007). LINks are set up at the interface between health and social care organizations and the local government area for which they are accountable (Hogg, 2007; Hughes, Mullen, \& Vincent-Jones, 2009; Martin, 2009). LINks are charged with bringing together the experiences and expectations of local people (factual dimension) and thereby identifying and passing on trends to the organizations responsible for delivering health and social care services (Department of Health, 2006). LINks were set up outside the chain of command of the NHS, hosted by an independent body under contract with the local authority (Hughes, Mullen, \& Vincent-Jones, 2009) but have the possibility to influence health care organizations at their management levels as they are entitled to a role in commissioning and contracting local services (social dimension) (Tritter, 2009). Moreover, health care organizations have statutory duties to respond to requests for information and to recommendations made by a LINk (Hughes, Mullen, \& Vincent-Jones, 2009).

The establishment of participatory community roles in health care organizations faces many difficulties which relate to ambiguities concerning the representation of community interests and the competence and commitment of representatives. Health care organizations are, therefore, often cautious and limit their engagement with community members (Martin \& Finn, 2011). Within organizations, persons are enrolled in specific roles and thus confronted with specific expectations. For community members to effectively become partners in decision processes it is essential to clarify how they represent the community, what skills and qualifications they are expected to bring to their engagement and how their commitment to participate over longer periods can be ensured. Recent case study research demonstrates that selection through "job descriptions" and contractual formalization of roles are mechanisms for successfully establishing a role for community members in decision-making processes at the "middle line" management level of health care organizations (ibid.).

\section{Discussion}


This article aims to contribute to the conceptual clarity of lay participation in health care organizations. Lay participation is about influencing decisions usually taken by professionals and by managers. Decisions on diagnosis, treatment and care of individual patients have been considered the domain of professionals (mainly medical doctors) who enjoy relative autonomy from managerial control. Decisions relating to service provision, quality assurance and resource allocation for particular conditions and the communities served are typically under managerial jurisdiction, but professional perspectives have to be considered too.

The rising relevance of lay participation for health care organizations stems from a series of demand side changes with which these organizations are confronted, such as the prevalence of chronic conditions, demographic changes, rising educational levels of the population, an expansion of the values underlining autonomy and self-determination, access to new information technologies etc. Traditional solutions - trust in professional expertise and bureaucratic control - have proven to be insufficient to meet these challenges. To better adjust services to needs, competencies, resources and the values of users and communities, to make them more responsive as well as effective, participation (voice) has been suggested as an alternative strategy to the expansion of consumer sovereignty and choice within market related concepts (see introduction). It was not our aim to join the voice vs. choice debate, but rather to demonstrate that lay participation in health care organizations can contribute to organizational innovation in a unique way. It can be seen as a main coupling mechanism of health care organizations with their lay environment, thereby becoming more responsive and adaptive to changes on the demand side. Yet at the same time, lay participation is a complex endeavor as it depends on creating different lay roles relating to different organizational decisions taken on different organizational levels.

Participation in health care organizations is more easily accomplished if it can be related to membership roles. As yet, the only firmly established lay role is the individual patient role. The role relation between patients and professionals has been undergoing a gradual transformation from highly asymmetric to a more balanced exchange of professional and lay (experiential) knowledge and differently based values. Co-production is gradually replacing professional dominance and shared decision-making has become a professional concept (Tritter, 2009), itself integrated into professional education, correlated with specific skills and supported by specific tools. There is also an emerging role for patient groups and organizations representing particular conditions and regular service usage. Representation, communicative competence and the stability of commitment for taking over a participatory role is, however, still a matter of debate, depending on the available support and advice for such groups. Patient groups and organizations might become involved in professionalmanagerial conflicts. As they often remain strongly allied to professionals, their ability to scrutinize professional work may be called into doubt. Giving significant others (carers) a role in health care decision-making can be argued in a similar way as individual patient participation for supporting the co-production of treatment. It gets more complex and may create ambiguity and uncertainty on the part of professionals when it substitutes for or contradicts patient participation. Establishing a participatory role for local communities seems to be the most demanding and complex issue for health care organizations. In general, user-related roles seem to be more easily adaptable for health care organizations 
than a role for local communities representing a variety of health needs and health related resources. Not surprisingly, a tendency for health care organizations to reduce this complexity by selecting community members who are acquainted with organizational procedures and more easily manageable has been reported (White, 2000).

Lay participation has long been predominantly understood as a power game following the perspective established by Arnstein (1969). This understanding is especially challenging in a context where the loyalty and trust of clients is a typical prerequisite for establishing role relations between professionals and clients (Stichweh, 2005; Vanderstraeten, 2007) and in organizations where the power-balance between professionals and management is a constant and delicate issue. A multi-dimensional conception of participation in decision processes has been argued as being helpful in acquiring a more differentiated understanding. Especially in a professional context, the "factual" dimension of decision processes becomes relevant as the knowledge and experience of patients and of significant others (carers) may provide a completely different perspective compared to professional knowledge and experience. Mutual exchange and support in groups of patients or carers can further enhance experiential knowledge and constitute collective experiential expertise. Deliberation among ordinary community members can raise awareness for common values such as equity (Murphy, 2007). As far as decision power (social dimension) is concerned, the role which lay people themselves wish to acquire has been given rather little attention (Thompson, 2007). However, there are various indications that people often prefer to be heard and to be taken into account in health care decisions, but not to be responsible for decisions others are paid to take (Litva et al., 2002; Rise et al., in press). Temporal aspects are also relevant to get the maximum out of lay participation: factual input is often especially relevant in the early phases of decision processes when problems are identified and defined (Labonte, 1997). Furthermore, expectations about continuity and intensity of participation must be adjusted realistically to the areas where lay participants can make a contribution.

Implementation of participatory lay roles in health care organizations must be considered as a challenge on its own. Even if organizations are ready to expand participatory practice, it won't happen without capacity building relating to participation. This issue could not be explored in detail in this article. Yet the experiences reported point to three devices organizations can use: (1) Developing competences and motivation of persons (professionals and other organizational staff, but also users and community representatives) through education, information and incentives (e.g. communication training, development of health literacy). (2) Developing programs by integrating the principle of participation into standards, guidelines and mission statements. (3) Integrating participation into organizational communication channels by establishing positions on boards, in departments etc. that are responsible for conducting participatory efforts and are equipped with adequate resources to establish and maintain them. While health care organizations have to do their part to make participation happen, collective participation of patient groups or communities in particular depends on capacities and opportunities which have to be developed in the political sphere and in civil society. 


\section{Conclusion}

Taking established frameworks of lay participation in health issues as the point of departure and applying bodies of theories on professions and organizations, several conceptual differentiations on roles, issues, functions and the implementation of lay participation were suggested for health care organizations. These may be considered as elements of a conceptual framework to further develop an understanding of the multifaceted participatory practices within an organizational context. This framework could encourage empirical research in accessing various forms of participatory practices, investigating their facilitators and constraints and examining their impacts on individuals and organizational programs and outcomes.

\section{References}

Abelson, J., Forest, P. G., Eyles, J., Smith, P., Martin, E., \& Gauvin, F. P. (2003). Deliberations about deliberative methods: Issues in the design and evaluation of public participation processes. Social Science \& Medicine, 57, 239-251.

Arnstein, S. R. (1969). A ladder of citizen participation. Journal of the American Institute of Planners, 35, 216-224.

Baggott, R., \& Forster, R. (2008). Health consumer and patients' organizations in Europe: Towards a comparative analysis. Health Expectations, 11, 85-94.

Barry, M., Levin, C., MacCuaig, M., Mulley, A., \& Sepucha, K. (2011). Shared decision making: Vision to reality. Health Expectations, 14, 1-5.

Borkman, T. (1976). Experiential knowledge: A new concept for the analysis of selfhelp groups. Social Service Review, 50, 445-456.

Cahill, P., \& Papageorgiou, A. (2007). Triadic communication in the primary care paediatric consultation: A review of the literature. British Journal of General Practice, 57, 904-911.

Charles, C., \& DeMaio, S. (1993). Lay participation in health care decision making: A conceptual framework. Journal of Health Politics, Policy and Law, 18, 881-904.

Charles, C., Gafni, A., \& Whelan, T. J. (1997). Shared decision-making in the medical encounter: What does it mean? (Or it takes at least two to tango). Social Science \& Medicine, 44, 681-692.

Church, J., Saunders, D., Wanke, M., Pong, R., Spooner, C., \& Dorgan, M. (2002). Citizen participation in health decision-making: Past experience and future prospects. Journal of Public Health Policy, 23, 12-32.

Cleary, M., Freeman, A., \& Walter, G. (2006). Carer participation in mental health service delivery. International Journal of Mental Health Nursing, 15, 189-194.

Coulter, A. (2002). The autonomous patient: Ending paternalism in medical care. London, England: Nuffield Trust.

Daigneault, P. M., \& Jacob, S. (2009). Toward accurate measurement of participation: Rethinking the conceptualization and operationalization of participatory evaluation. American Journal of Evaluation, 30, 330-348. 
Department of Health. (2006). A stronger local voice: A framework for creating a stronger local voice in the development of health and social care services (A document for information and comment). London, England: Department of Health, NHS.

Edwards, A., \& Elwyn, G. (2006). Inside the black box of shared decision making: Distinguishing between the process of involvement and who makes the decision. Health Expectations, 9, 307-320.

Elwyn, G., \& Miron-Shatz, T. (2010). Deliberation before determination: The definition and evaluation of good decision making. Health Expections, 13, 139-147.

Fafard, P., Rocher, F., \& Côté, C. (2009). Clients, citizens and federalism: A critical appraisal of integrated service delivery in Canada. Canadian Public Administration, 52, 549-568.

Forbat, L., Hubbard, G., \& Kearney, N. (2009). Patient and public involvement: Models and muddles. Journal of Clinical Nursing, 18, 2547-2554.

Forster, R., Braunegger-Kallinger, G., \& Krajic, K. (2011). Austrian health consumer groupsVoices gaining strength? In H. Löfgren, E. De Leeuw, \& M. Leahy (Eds.), Democratizing health: Consumer groups in the policy process (pp. 143-160). Cheltenham, UK: Edward Elgar.

Forster, R., \& Gabe, J. (2008). Voice or choice? Patient and public involvement in the national health service in England under new Labour. International Journal of Health Services, 38, 333-356.

Gabe, J., Olumide, G., \& Bury, M. (2004). 'It takes three to tango': A framework for understanding patient partnership in paediatric clinics. Social Science \&Medicine, 59, 1071-1079.

Gauvin, F. P., Abelson, J., Giacomini, M., Eyles, J., \& Lavis, J. N. (2010). "It all depends": Conceptualizing public involvement in the context of health technology assessment agencies. Social Science \& Medicine, 70, 1518-1526.

Gerhards, J. (2001). Der Aufstand des Publikums. Eine systemtheoretische Interpretation des Kulturwandels in Deutschland zwischen 1960 und 1989 [The rebellion of the citizens: A systemtheoretical interpretation of cultural change of the German society (1960-1989)]. Zeitschrift für Soziologie, 30, 163-184.

Hasenfeld, Y. (1983). Human service organizations. Upper Saddle River, NJ: Prentice-Hall.

Hogg, C. N. L. (2007). Patient and public involvement: What next for the NHS? Health Expectations, 10, 129-139.

Hughes, D., Mullen, C., \& Vincent-Jones, P. (2009). Choice vs. voice? PPI policies and the repositioning of the state in England and Wales. Health Expectations, 12, 237-250.

Hunter, D. J. (2006). From tribalism to corporatism: The continuing managerial challenge to medical dominance. In D. Kelleher, J. Gabe, \& G. Williams (Eds.), Challenging medicine (2nd ed., pp. 1-24). New York, NY: Routledge.

Kelleher, D. (2006). Self-help groups and their relationship to medicine. In D. Kelleher, J. Gabe, \& G. Williams (Eds.), Challenging medicine (2nd ed., pp. 104-121). London, England: Routledge.

Kirkpatrick, I., Dent, M., \& Jespersen, P. K. (2011). The contested terrain of hospital management: Professional projects and healthcare reforms in Denmark. Current Sociology, 59, 489-506. 
Labonte, R. (1997).Power, participation and partnership for health promotion. Victoria, Australia: Victorian Health Promotion Foundation.

Le Grand, J. (2007). The other invisible hand: Delivering public services through choice and competition. Princeton, NJ: Princeton University Press.

Litva, A., Canvin, K., Shepherd, M., Jacoby, A., \& Gabbay, M. (2009). Lay perceptions of the desired role and type of user involvement in clinical governance. Health Expectations, 12, 81-91.

Litva, A., Caost, J., Donovan, J., Eyles, J., Sheperd, M., Tacchi, J., \& Morgan, K. (2002). 'The public is too subjective': Public involvement at different levels of health-care decision making. Social Science \& Medicine, 54, 1825-1837.

Llewellyn-Jones, L., \& Harvey, D. (2005). The development of a health promotion community participation framework. Australian Journal of Primary Health, 11(2), 136-146.

Löfgren, H., De Leeuw, E., \& Leahy, M. (Eds.). (2011). Democratizing health: Consumer groups in the policy process. Cheltenham, UK: Edward Elgar.

Luhmann, N. (1995). Social systems. Stanford, CA: Stanford University Press.

Luhmann, N. (2003). Organization. In T. Bakken \& T. Hernes (Eds.). Autopoietic organization theory (pp. 31-52). Copenhagen, Denmark: Copenhagen Business School Press.

Martin, G. P. (2009). Whose health, whose care, whose say? Some comments on public involvement in NHS commissioning arrangements. Critical Public Health, 19, 123-132.

Martin, G. P., \& Finn, R. (2011). Patients as team members: Opportunities, challenges and paradoxes of including patients in multi-professional healthcare teams. Sociology of Health \& IIIness, 33, 1050-1065.

McKee, M., Healy, J., Edwards, N., \& Harrison, A. (2002). Pressures for change. In M. McKee \& J. Healy (Eds.), Hospitals in a changing Europe (pp. 36-58). Buckingham, UK: Open University Press.

Mintrom, M. (2003). Market organizations and deliberative democracy: Choice and voice in public service delivery. Administration \& Society, 35, 52-81.

Mintzberg, H. (1979). The structuring of organizations. Englewood Cliffs, NJ: Prentice-Hall.

Murphy, N. J. (2005). Citizen deliberation in setting health-care priorities. Health Expectations, 8, 172-181.

Numerato, D., Salvatore, D., \& Fattore, G. (2012). The impact of management on medical professionalism: A review. Sociology of Health \& Illness, 34, 626-664.

Oliver, S. R., Rees, R. W., Clarke-Jones, L., Milne, R., Oakley, A. R., Gabbay, J., \& Gyte, G. (2008). A multidimensional conceptual framework for analyzing public involvement in health services research. Health Expectations, 11, 72-84.

Rapley, T. (2008). Distributed decision making: The anatomy of decisions-in-action. Sociology of Health \& IIIness, 30, 429-444.

Rise, M. B., Solbjor, M., Lara, M. C., Westerlund, H., Grimstad, H., \& Steinsbekk, A. (2011). Same descriptions, different values. How services users and providers define patient and public involvement. Health Expections. Advance Online Publication. doi:10.1111/j.13697625.2011.00713.x

Simovska, V., \& Jensen, B. B. (2009). Conceptualizing participation-the health of children and young people. Copenhagen, Denmark: WHO Regional Office for Europe. 
Stichweh, R. (2005). Wissen und die professionen in einer organisationsgesellschaft [Knowledge and the professions in an organisation society]. In T. Klatetzki \& V. Tacke (Eds.), Organisation und profession (pp. 31-44). Wiesbaden: Verlag für Sozialwissenschaften.

Tambuyzer, E., Pieters, G., \& Van Audenhove, C. (2011). Patient involvement in mental health care: One size does not fit all. Health Expectations. Advance Online Publication. doi:10.1111/j.1369-7625.2011.00743.x

Tenbensel, T. (2010). Virtual special issue introduction: Public participation in health policy in high income countries - A review of why, who, what, which, and where? Social Science \& Medicine, 71, 1537-1540.

Thompson, A. G. H. (2007). The meaning of patient involvement and participation in health care consultations: A taxonomy. Social Science \& Medicine, 64, 1297-1310.

Tritter, J. Q. (2009). Revolution or evolution: The challenges of conceptualizing patient and public involvement in a consumerist world. Health Expectations, 12, 275-287.

Tritter, J. Q., \& McCallum, A. (2006). The snakes and ladders of user involvement: Moving beyond Arnstein. Health Policy, 76, 156-168.

Trojan, A., \& Nickel, S. (2011). Integration von Selbsthilfefreundlichkeit in das Gesundheitswesen-Entwicklungen und Perspektiven [Integration of self-help associations into the health services system-Developments and perspectives]. Das Gesundheitswesen, 73, 67-72.

van de Bovenkamp, H. M., Trappenburg, M. J., \& Grit, K. J. (2009). Patient participation in collective healthcare decision making: The Dutch model. Health Expectations, 13, 73-85.

Vanderstraeten, R. (2007). Professions in organizations, professional work in education. British Journal of Sociology of Education, 28, 621-635.

van Staa, A. (2011). Unraveling triadic communication in hospital consultations with adolescents with chronic conditions: The added value of mixed methods research. Parent Education and Counseling, 82, 455-464.

Weick, K. E. (1979). Social psychology of organizing. Boston, MA: McGraw-Hill.

White, D. (2000). Consumer and community participation: A reassessment of process, impact and value. In G. L. Albrecht, R. Fitzpatrick, \& S. C. Scrimshaw (Eds.), Handbook of social studies in health and medicine (pp. 465-480). London, England: SAGE.

WHO (1978). Alma Ata Declaration. Copenhagen, Denmark: WHO Regional Office for Europe. Witz, A., \& Annandale, E. (2006). The challenge of nursing. In D. Kelleher, J. Gabe, \& G. Williams (Eds.), Challenging medicine (2nd ed., pp. 24-39). London, England: Routledge.

Wright, M. T., Block, M., \& von Unger, H. (2008). Partizipation in der Zusammenarbeit zwischen Zielgruppe, Projekt und Geldgeber [Participation in the cooperation between target group, project and sponsor]. Das Gesundheitswesen, 70, 748-754. 